\title{
Mild Rectal Dysplasia
}

National Cancer Institute

\section{Source}

National Cancer Institute. Mild Rectal Dysplasia. NCI Thesaurus. Code C4851.

A morphologic finding indicating the presence of mild dysplastic cellular changes and mild architectural changes in the glandular epithelium of the rectal mucosa. There is no evidence of invasion. 